\title{
Linkages, fields of influence and key sectors
}

\author{
Thijs ten Raa*
}

\author{
${ }^{*}$ Correspondence: \\ tenraa@uvt.nl \\ Utrecht University, Utrecht, \\ The Netherlands
}

\section{Abstract \\ Linkages, fields of influence and key sectors are troublesome concepts.}

Keywords: Linkages, Fields of influence, Key sectors

JEL Classification: C67

\section{Introduction}

Backward linkages measure the impact of final demand changes on output. Forward linkages measure the impact of value-added changes on price. Backward linkages are given by the column totals of the Leontief inverse and forward linkages by the row totals. Industries with higher linkages have more influence on the economic system, and industries with above average backward linkage and above average forward linkage are deemed key sectors. The extensive literature on these concepts is a playground for fanciers of matrix algebra and, not surprisingly, is a flourishing subfield of input-output analysis. With due respect to the practitioners I address the question if all this hard theoretical work is useful. I have three worries.

\section{Worry \# 1}

Linkages, influence and key sectors all have positive connotation. The concepts identify important industries, which impact the economy. Such industries have big multiplier effects, which are supposed to be good to the economy. Big multipliers mean big entries in the Leontief inverse. Now there is an increasing relationship between the Leontief inverse and the underlying intermediate input coefficients (as the Neumann series clearly demonstrates). So having big multipliers is equivalent to having big input coefficients. Frankly, I would rather live in an economy with small input coefficients. Then industries need little and leave much to the consumers. After all an economy is a machine that transforms resources into household consumption, the objective to be fulfilled. The aforementioned literature ignores that. The fascination with high multipliers is perverse. Industries are important if they contribute directly or indirectly to household consumption; value added is a better indicator than the magnitude of intermediate input coefficients. The standard macroeconomic policy to focus on industries with high input coefficients is simplistic. Moreover, income multipliers boost industrial multipliers, in fact in a uniform way (ten Raa 2005, Theorem 3.1). Last but not least, in 
a multiregional economy comparative advantages better be factored in when the importance of industries is assessed (e.g., ten Raa and Pan 2005).

\section{Worry \# 2}

Intermediate input coefficients and multipliers are intermediate constructs in economic analysis and better be commingled with factor input coefficients. This is even true in disequilibrium analysis where, for example, an industry is targeted to boost labor employment. The labor employment multipliers are given by the product of the (row vector of) labor coefficients and the Leontief inverse. It is not enough that a target industry has big output multipliers. Actually, it is not relevant. The product of the (row vector of) labor coefficients and the target industry column of the Leontief inverse must be big.

\section{Worry \# 3}

Column totals of the Leontief inverse (backward linkages) and row totals (forward linkages) are suspicious from a measurement perspective. Apples and oranges are added. This is particularly true of column totals, where different products are added (backward linkages). However, even row totals (forward linkages) have this defect.

A simple example illustrates my discussion. Consider the matrix of intermediate input coefficients $\left(\begin{array}{lll}0 & 1 & 0 \\ 0 & 0 & 1 \\ 0 & 0 & 0\end{array}\right)$. Its Leontief inverse is $\left(\begin{array}{lll}1 & 1 & 1 \\ 0 & 1 & 1 \\ 0 & 0 & 1\end{array}\right)$. The row totals are $\left(\begin{array}{l}3 \\ 2 \\ 1\end{array}\right)$ and the column totals $\left(\begin{array}{lll}1 & 2 & 3\end{array}\right)$. Sonis et al. $(1997,2000)$ consolidate multipliers, influences and linkages by taking the product matrix of the two: $\left(\begin{array}{lll}3 & 6 & 9 \\ 2 & 4 & 6 \\ 1 & 2 & 3\end{array}\right)$.

Two findings are the following. The industry hierarchy in terms of forward linkages (row totals) is (i) industry 1, (ii) industry 2 , and (iii) industry 3 . The multipliers' product matrix shows that industries 1 and 3 have equal influence: the products of their own multipliers are equal (the first and the third diagonal entries), as are their fields of influence (1, 2, 6, 9 in the first row and column, as well as in the third row and column).

I claim the findings are not invariant with respect to the units of measurement. To prove this, I measure product 2 in a different unit. For example, the old unit was kilogram and the new unit is metric pound (which is $500 \mathrm{~g}$ ). The input-output matrix becomes $\left(\begin{array}{ccc}0 & 1 / 2 & 0 \\ 0 & 0 & 2 \\ 0 & 0 & 0\end{array}\right)$. The Leontief inverse becomes $\left(\begin{array}{ccc}1 & 1 / 2 & 1 \\ 0 & 1 & 2 \\ 0 & 0 & 1\end{array}\right)$. The row multipliers become $\left(\begin{array}{c}2.5 \\ 3 \\ 1\end{array}\right)$ and the column multipliers become $\left(\begin{array}{lll}1 & 1.5 & 4\end{array}\right)$. The multipliers product matrix becomes $\left(\begin{array}{ccc}2.5 & 3.75 & 10 \\ 3 & 4.5 & 12 \\ 1 & 1.5 & 4\end{array}\right)$.

Let me check the two findings. The industry hierarchy in terms of forward linkages (row totals) is now: (i) industry 2, (ii) industry 1 , and (iii) industry 3 . That is different than before I changed the unit of measurement. And industries 1 and 3 now have unequal influence: the products of their row and column multipliers are now 2.5 and 4, respectively. And their cross-effects are 1, 3, 3.75 and 10 for industry 1, and 1, 1.5, 12 
and 10 for industry 3 . So industry 3 now has more influence than industry 1 . That is also different.

\section{Conclusion}

I have changed the importance of industries in terms of linkages and fields of influence just by measuring the output of an industry in metric pounds instead of kilograms. The concepts of linkages and fields of influence are not invariant with respect to the units of measurement. Key sectors are a derived concept, and therefore, have the same defect, as have the concepts of construction importance (Jensen and West 1980) and social accounting-based impacts (Pyatt and Round 1979).

All these are reminiscent of ten Raa et al. (1984) finding that some methods of constructing input coefficients are not invariant with respect to the units of measurement. That spurred a lot of theory, which eventually solved the problem (Rueda-Cantuche 2017). I hope some readers take up the challenge to rethink linkages, fields of influence and key sectors.

Acknowledgements

None.

Authors' contributions

The author read and approved the final manuscript.

Funding

None.

Availability of data and materials

Not applicable.

Competing interests

The author declares no competing interests.

Received: 17 July 2019 Revised: 31 January 2020 Accepted: 11 April 2020

Published online: 16 April 2020

References

Jensen RC, West GR (1980) The effect of relative coefficient size on input-output multipliers. Environ Plan A 12(6):659-670

Pyatt G, Round JI (1979) Accounting and fixed price multipliers in a social accounting matrix framework. Econ J 89(356):850-873

Rueda-Cantuche JM (2017) The construction of input-output coefficients. In: ten Raa T (ed) Handbook of input-output analysis. Edward Elgar, Cheltenham, pp 133-174

Sonis M, Hewings GJD, Guo J (1997) Comparative analysis of China's metropolitan economies: an input-output perspective. In: Chatterji M, Kaizhong Y (eds) Regional science in developing countries. Macmillan Press, Basingstoke, pp $147-162$

Sonis M, Hewings GJD, Guo J (2000) A new image of classical key sector analysis: minimum information decomposition of the leontief inverse. Econ Syst Res 12(3):401-423

ten Raa T (2005) The economics of input-output analysis. Cambridge University Press, Cambridge

ten Raa T, Pan H (2005) Competitive pressures on China: income inequality and migration. Reg Sci Urban Econ 35(6):671-699

ten Raa T, Chakraborty D, Small JA (1984) An alternative treatment of secondary products in input-output analysis. Rev Econ Stat 66(1):88-97

\section{Publisher's Note}

Springer Nature remains neutral with regard to jurisdictional claims in published maps and institutional affiliations. 